\title{
5-FU targets rpL3 to induce mitochondrial apoptosis via cystathionine- $\beta$-synthase in colon cancer cells lacking p53
}

\author{
Valentina Pagliara ${ }^{1}$, Assunta Saide ${ }^{1}$, Emma Mitidieri $^{1}$, Roberta d'Emmanuele di \\ Villa Bianca ${ }^{1}$, Raffaella Sorrentino ${ }^{1}$, Giulia Russoํㅜ, Annapina Russo ${ }^{1}$ \\ ${ }^{1}$ Department of Pharmacy, University of Naples "Federico II", 80131 Naples, Italy \\ Correspondence to: Annapina Russo, email: annapina.russo@unina.it \\ Keywords: nucleolar stress, p53, CBS, colon cancer, apoptosis
}

Received: April 29, $2016 \quad$ Accepted: June 18, $2016 \quad$ Published: July 2, 2016

\section{ABSTRACT}

Recent findings revealed in cancer cells novel stress response pathways, which in response to many chemotherapeutic drugs causing nucleolar stress, will function independently from tumor protein p53 (p53) and still lead to cell cycle arrest and/ or apoptosis. Since it is known that most cancers lack functional p53, it is of great interest to explore these emerging molecular mechanisms. Here, we demonstrate that nucleolar stress induced by 5-fluorouracil (5-FU) in colon cancer cells devoid of p53 leads to the activation of ribosomal protein L3 ( $r p L 3)$ as proapoptotic factor. rpL3, as ribosome-free form, is a negative regulator of cystathionine- $\beta$-synthase (CBS) expression at transcriptional level through a molecular mechanism involving Sp1. The rpL3-CBS association affects CBS stability and, in addition, can trigger CBS translocation into mitochondria. Consequently apoptosis will be induced through the mitochondrial apoptotic cell death pathway characterized by an increased ratio of Bax to $\mathrm{Bcl}-2$, cytochrome $\mathrm{c}$ release and subsequent caspase activation. It is noteworthy that silencing of CBS is associated to a strong increase of 5-FU-mediated inhibition of cell migration and proliferation. These data reveal a novel mechanism to accomplish p53-independent apoptosis and suggest a potential therapeutic approach aimed at upregulating rpL3 for treating cancers lacking p53.

\section{INTRODUCTION}

Colorectal cancer represents the third most frequently diagnosed malignancy in the world [1]. Despite recent advances in chemotherapy, currently used anticancer molecules are unable to improve the prognosis of advanced or recurrent colon cancer, which remains incurable. The anti-metabolite agent 5-FU is a widely used chemotherapeutic drug for the treatment of a variety of solid tumors [2] and it remains the standard first-line drug for the treatment of colon cancer [3]. Recently, some evidences indicate that 5 -FU is able to induce ribosomal stress and disruption of the nucleolus with the consequent release of some ribosomal proteins that, exerting extra-ribosomal functions [4], in turn activate p53 and its target p21. It is known that most cancer cells contain mutant p53 or null p53 [5]. p53 mutations have been described in $70 \%$ of colon cancer [6]. Several studies have demonstrated that the loss of $\mathrm{p} 53$ function reduced cellular sensitivity to 5-FU [2]; however, the molecular mechanism by which this occurs is still a matter of debate [7]. Therefore, a better understanding of the p53 independent molecular mechanisms of 5-FU effects on cancer cells could contribute to improve the therapy of colon cancer. Recently, we have demonstrated that human $\mathrm{rpL} 3$ is able to activate the transcription of $\mathrm{p} 21$ in a p53independet manner [8]. In addition, we have demonstrated that rpL3 acts as a stress sensing molecule essential for cell response to 5-FU treatment in colon cancer cells lacking active p53. In particular, our results indicated that $\mathrm{rpL} 3$ overexpression is able to improve the cytotoxic effects of 5-FU, which acts as DNA damage agent inducing apoptosis. Conversely, the loss of rpL3 makes chemotherapeutic effects of this drug ineffective $[9,10]$.

Clinical and epidemiological studies have evaluated the relationship between hydrogen sulfide $\left(\mathrm{H}_{2} \mathrm{~S}\right)$ and colon cancer demonstrating that, in cancer cells a molecular switch comprised of $\mathrm{H}_{2} \mathrm{~S}$ and Nicotinamide phosphoribosyltransferase (Nampt) is responsible for modifications of phenotype, of gene expression pattern and dedifferentiation $[11,12]$.

$\mathrm{H}_{2} \mathrm{~S}$ intracellular biosynthesis is enzymatically regulated. It is generated from L-cysteine by two pyridoxal- 
5'-phospate-dependent (PLP) enzymes, cystathionine$\beta$-synthase (CBS) and cystathionine- $\gamma$-lyase (CSE), and in PLP independent manner by the combined action of cysteine aminotransferase and 3-mercaptopyruvate sulfurtransferase (3-MST) [13].

It has been recently demonstrated that CBS is abundantly expressed in human colon cancer cell lines and in human colon cancer tissue specimens, resulting in increased $\mathrm{H}_{2} \mathrm{~S}$ production [14]. CBS activity is tightly regulated at the transcriptional level [15]. Among the transcription factors, Sp1 represents a key regulator involved in the control of CBS transcription [16]. We have previously demonstrated that free $\mathrm{rpL} 3$ associates to $\mathrm{Sp} 1$ modulating the transcriptional factor activity [8].

Given these observations, in the attempt to characterize the molecular mechanism underlying rpL3mediated cell response to 5-FU chemotherapy in colon cancer, we have investigated the existence of a regulatory mechanism of CBS expression mediated by rpL3. Here we provide for the first time evidences supporting the existence of a new extraribosomal function of $\mathrm{rpL} 3$, that is its regulatory role on the expression of the cytosolic enzyme CBS. In particular we demonstrate that in presence of 5-FU induced nucleolar stress, ribosome free $\mathrm{rpL} 3$ is able to: i) downregulate Sp1-mediated CBS transcription; ii) trigger mitochondrial translocation of CBS; iii) modify CBS protein stability; iv) induce mitochondrial apoptosis mediating the increase of $\mathrm{Bax} / \mathrm{Bcl}-2$ ratio, cytochrome $\mathrm{c}$ release and caspase activation.

\section{RESULTS}

\section{Role of $\mathrm{rpL3}$ in the $\mathrm{CBS} / \mathrm{H}_{2} \mathrm{~S}$ axis in colon cancer cells}

In order to identify the rpL3 molecular targets that mediate its pro-apoptotic function upon drug-induced nucleolar stress [8-10], we became interested to assess the intracellular levels of CBS after 5-FU treatment in human colon cancer cells devoid of $\mathrm{p} 53$. To this aim, HCT $116^{\mathrm{p} 53-}$ / cells and rpL3 3 HCT $116^{\text {p53-- }}$ cells, a cell line stably depleted of rpL3, were treated with $100 \mu \mathrm{M} 5$-FU for 24 h. After the treatment, the cells were lysated and protein extracts were analyzed by western blotting.

The Figure 1A shows that in HCT $116^{\text {p53-/ }}$ cells 5 -FU treatment caused the up-regulation of $\mathrm{rpL} 3$ expression levels, as previously demonstrated [9], coupled to the down-regulation of CBS protein levels. The observed CBS decrease was associated to a significant reduction of $\mathrm{H}_{2} \mathrm{~S}$ biosynthesis (Figure 1B). Of note, alterations of CBS protein amounts were also observed upon 5-FU treatment in condition of $\mathrm{rpL} 3$ depletion. In fact, densitometric analysis of western blots revealed that the loss of rpL3 was associated to a significant increase of CBS expression levels with comparable higher production of $\mathrm{H}_{2} \mathrm{~S}$ (Figure 1A,B).
These results indicate that the effect of 5-FU on CBS expression occurs through a molecular mechanism specifically mediated by rpL3.

\section{rpL3 regulates CBS expression at transcriptional level}

We have recently demonstrated that, after drug induced nucleolar stress, the ribosome-free $\mathrm{rpL} 3$ was able to act as transcriptional factor [8-10]. Consequently we became interested to determine whether the rpL3mediated regulation of CBS protein levels was consequent to the rpL3 control on the activity of CBS promoter. To this aim, total RNA from untreated and 5-FU treated HCT $116^{\text {p53-/ }}$ and $\mathrm{rpL} 3 \triangle \mathrm{HCT} 116^{\mathrm{p} 53-/-}$ cells was isolated and CBS mRNA levels were quantified by using RT-qPCR. We found a decrease (about 40\%) in CBS mRNA levels upon 5-FU treatment in HCT $116^{\mathrm{p} 33-/-}$ cells (Figure 2A). Of note, the rpL3 loss and 5-FU treatment cooperate to produce a strong increase of CBS mRNA amounts. These results suggest a role of rpL3 as regulatory factor of CBS transcription. The expression of CBS gene is mainly regulated, at transcriptional level, by Sp1 [16] and we have previously demonstrated that rpL3 interacts with $\mathrm{Sp} 1$ [8]. In order to verify if a specific interaction between these two proteins also occurred upon 5-FU induced nucleolar stress, HCT $116^{\mathrm{p} 53-/-}$ cells untreated or treated with 100 $\mu \mathrm{M} 5$-FU for $24 \mathrm{~h}$, were collected and protein extracts subjected to immunoprecipitation experiments by using anti-Sp1 and anti-IgG as control. Immunoprecipitated proteins were separated by SDS-PAGE and the presence of Sp1 and rpL3 was investigated in the immunoprecipitated complexes by western blotting. The Figure 2B shows that in untreated cells rpL3 interacted with $\mathrm{Sp} 1$ as previously demonstrated [8]. A specific binding of rpL3 with Sp1 was also observed after 5-FU treatment.

To gain insights into the mechanism by which rpL3 was associated to reduction of CBS mRNA levels and in order to understand whether rpL3-Sp1 interaction played a role in CBS transcription, we studied the effects of alterations in rpL3 intracellular levels on Sp1 binding to the CBS promoter by performing ChIP experiments. We specifically immunoprecipitated Sp1 from HCT $116^{\text {p53-- }}$ and rpL3 3 HCT $116^{\text {p53-/ }}$ cells treated with $100 \mu \mathrm{M} 5$-FU for $24 \mathrm{~h}$. Results from qPCR assays on the samples indicated that in untreated cells, the transcriptional activator Sp1 binds CBS promoter (Figure 2C), as previously demonstrated [16]. In 5-FU treated cells, the binding of Sp1 on CBS promoter was significantly decreased compared to that observed in the control (Figure 2C). Noteworthy, in rpL3 depleted cells either 5-FU treated or untreated, the interaction of $\mathrm{Sp} 1$ with CBS promoter was strongly increased, indicating a reorganization of the protein complexes on the promoter. These data imply that the interaction of Sp1 with CBS promoter is affected by rpL3 status. 
A
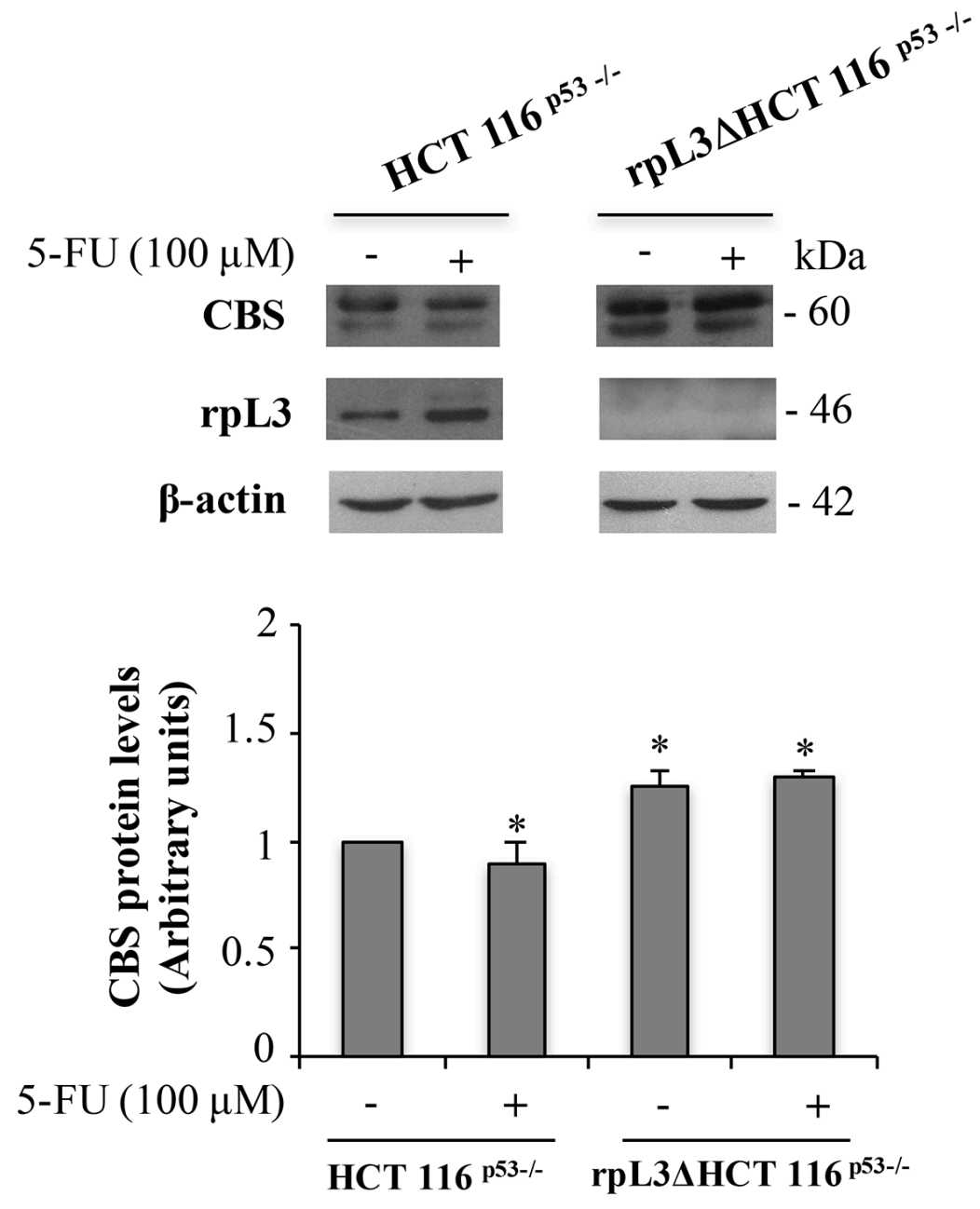

B

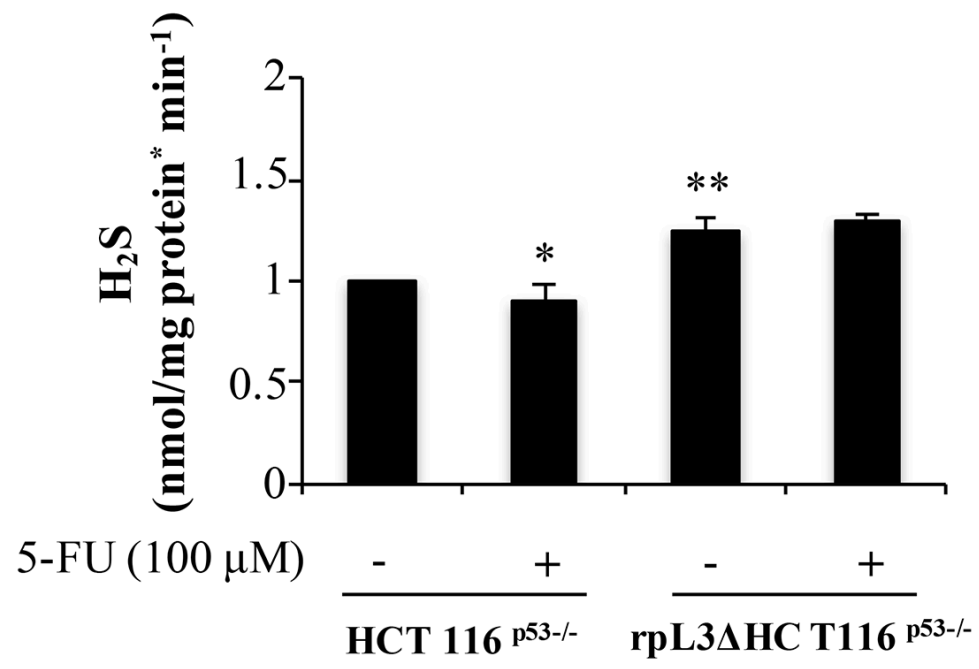

Figure 1: 5-FU induced rpL3 down-regulates CBS expression levels and H2S production. A. Western blotting of rpL3 and CBS protein expression. HCT $116^{\text {p53-/ }}$ and rpL3 $\Delta$ HCT $116^{\text {p33-/ }}$ cells were treated or not with $100 \mu \mathrm{M} 5$-FU for 24 h. Protein extracts from the samples were analyzed by western blotting with antibodies against rpL3 and CBS. $\beta$-actin was used as loading control. Quantification of signals is shown. $* \mathrm{P}<0.05$ vs. untreated HCT $116^{\mathrm{p} 33-/}$ cells. B. Production of $\mathrm{H}_{2} \mathrm{~S}$ from the same samples. ${ }^{* *} \mathrm{P}<0.01, * \mathrm{P}<0.05$ vs. untreated HCT $116^{\text {p53-/ }}$ cells. Results illustrated in Figure 1-7 are representative of three independently performed experiments. 
A

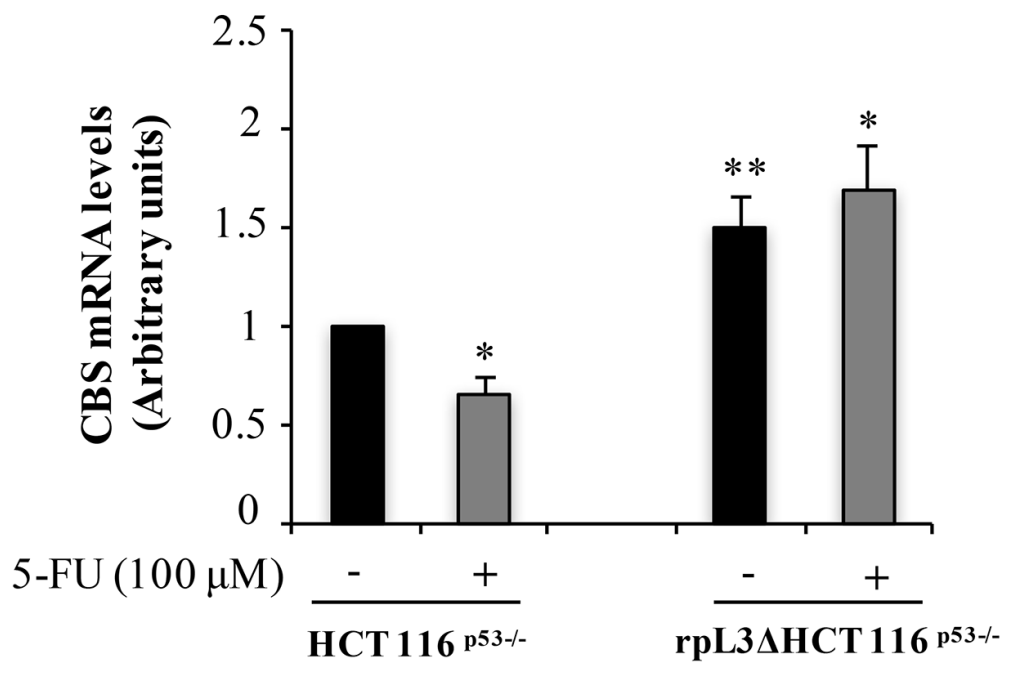

B

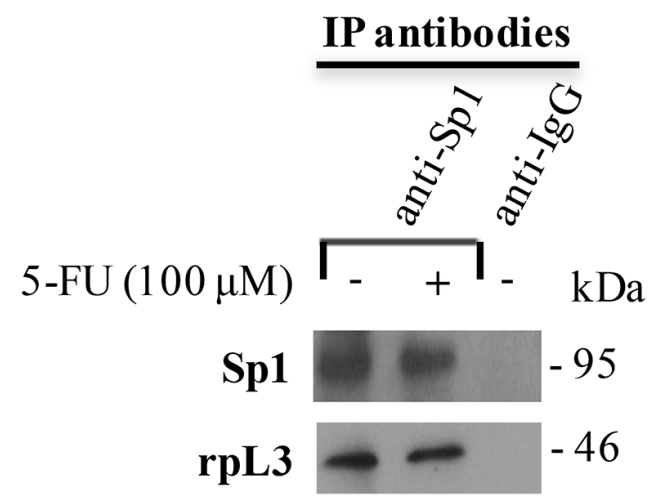

C

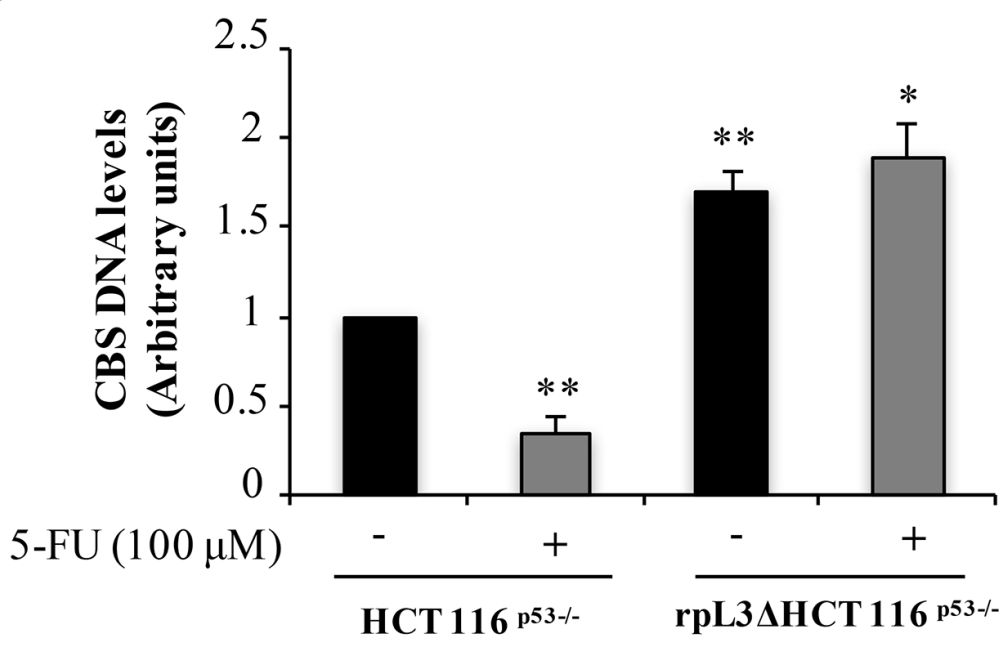

Figure 2: Upon 5-FU treatment, the interaction of rpL3 with Sp1 impairs its binding to CBS promoter and leads to a decrease of CBS mRNA levels. A. Total RNA from HCT $116^{\text {p53-l }}$ cells untreated or treated with $100 \mu \mathrm{M} 5$-FU for $24 \mathrm{~h}$ was subjected to qPCR with primers specific for CBS mRNA. Quantification of signals is shown. ${ }^{* *} \mathrm{P}<0.01,{ }^{*} \mathrm{P}<0.05$ vs. untreated HCT $116^{\text {p53-- }}$ cells. B. Analysis of the interaction between rpL3 and Sp1. Protein samples of Sp1 or IgG immunocomplexes from HCT $116^{\text {p33-/ }}$ cells untreated or treated with $100 \mu \mathrm{M}$ 5-FU for $24 \mathrm{~h}$ were analyzed by western blotting with antibodies against Sp1 and rpL3. Note the absence of signal in IgG immunocomplex. C. Analysis of the interaction between Sp1 and CBS gene promoter. DNA-Sp1 or DNA-IgG immunocomplexes from

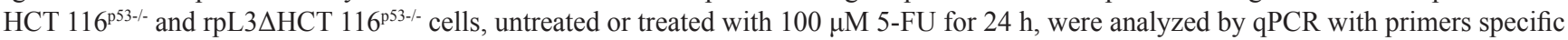
for CBS gene promoter. Quantification of the signals is shown. ${ }^{*} \mathrm{P}<0.01,{ }^{*} \mathrm{P}<0.05$ vs. untreated HCT $116^{\mathrm{p} 53-/}$ cells. 


\section{rpL3 binds CBS in vivo and controls CBS stability}

We next investigated the possibility that $\mathrm{rpL} 3$ and CBS could associate in vivo. To this aim, HCT $116^{\text {p53- }}$ / cells were treated with $100 \mu \mathrm{M} 5$-FU for $24 \mathrm{~h}$. Then, rpL3 and CBS were specifically immunoprecipitated from cell extracts by using antibodies against the endogenous proteins. Immunoprecipitated proteins were separated by SDS-PAGE and analyzed by western blotting with anti-rpL3, anti-CBS and as controls anti-rpL7a and antirpS19 two arbitrary proteins of large and small subunit, respectively. The results of these experiments showed that rpL3 and CBS were co-immunoprecipitated thus indicating that they can associate in vivo, notably this interaction was strongly enhanced after 5-FU treatment (Figure 3A).

Furthermore, the absence of signal for $\mathrm{rpL} 7 \mathrm{a}$ and rpS19 in both immunoprecipitates indicated that the free $\mathrm{rpL} 3$, not associated into ribosome, is able to interacts with CBS. A control immunoprecipitate obtained with anti-IgG antibodies did not give any signal when probed with the same antibody.

To verify whether the interaction of rpL3 and CBS affected CBS turnover and, in particular, to determine whether rpL3 was essential to maintain CBS intracellular abundance, we examined the level of CBS in HCT $116^{\text {p53-/ }}$ and rpL3 $\Delta$ HCT $116^{\text {p53-/ }}$ cells. To this aim, cells were incubated with cycloheximide for various times $(0.5,1,1.5,2 \mathrm{~h})$. After the incubation, cells were harvested, lysated and the level of CBS was determined by western blot analysis. The results illustrated in Figure 3B demonstrate that the half-life of CBS was greater in cells upon rpL3 silencing. All together these data indicate that $\mathrm{rpL} 3$ physically interacts with CBS and induces its degradation.

\section{Role of rpL3 in mitochondrial apoptosis upon 5-FU treatment}

The induction of apoptosis is a standard strategy used in anticancer therapy [18]. Recently, we have shown a proapoptotic function of rpL3 [9], and other authors have demonstrated that the downregulation of CBS triggers mitochondrial apoptosis [17]. In order to investigate the factors leading to the $\mathrm{rpL} 3$-induced apoptosis in HCT 116 $6^{\text {p53-/ }}$ cells upon 5-FU treatment, we primarily determined the effect of 5-FU-induced free rpL3 on activities of apoptosis-related proteins of the mitochondria-mediated pathway. This pathway contains several members, including the anti-apoptotic protein, $\mathrm{Bcl}-2$ and the apoptosis-promoting protein, Bax. The ratio $\mathrm{Bcl}-2 / \mathrm{Bax}$ is used to evaluate the occurrence and severity of apoptosis [18]. To this aim, HCT $116^{\text {p53-/ }}$ and $\operatorname{rpL} 3 \Delta$ HCT $116^{\text {p53-/ }}$ cells were treated with 5 -FU $100 \mu \mathrm{M}$ for $24 \mathrm{~h}$. Then, cells were lysated and protein extracts were analysed by western blotting for the expression profile of procaspase-3, Bcl-2 and Bax.

The Figure 4 shows a marked decrease of Bcl-2 levels associated to an increase of Bax amounts in HCT $116^{\text {p53-/ }}$ cells treated with 5-FU as compared to untreated cells. These data are in good correlation with the apoptosis induced in HCT $116^{\text {p53-/ }}$ cells by 5 -FU. Of interest, these effects were not obeserved when we treated $\operatorname{rpL} 3 \Delta \mathrm{HCT}$ $116^{\mathrm{p} 53-/}$ cells with 5 -FU.

Caspase apoptosis proteins are activated when the ratio $\mathrm{Bcl}-2 / \mathrm{Bax}$ is reduced [19], therefore we analyzed the expression of caspase- 3 which is a key regulator in the caspase-dependent cell apoptosis pathway [20,21]. Consistent with the higher apoptotic ability of the treated cells, the presence of the active caspase- 3 form, which is proteolytically generated during apoptosis, was observed. These findings add strength to the hypothesis that the involvement of a caspase-dependent pathway through a caspase-3-triggered mitochondrial pathway may lead to rpL3-mediated apoptosis.

\section{rpL3 triggers CBS translocation to mitochondria upon 5-FU treatment}

In order to investigate the sorting of rpL3 to specific subcellular regions in condition of 5-FU-induced nucleolar stress, we used a subcellular fractionation procedure. Using biochemical techniques, we isolated from HCT $116^{\text {p53-/ }}$ cells two distinct fractions corresponding to the cytosolic fraction (CF) and the mitochondrial fraction (MF). These two fractions were assayed for lactate dehydrogenase (LDH), a marker component of the CF [22], and ATPase as control of the MF. Since LDH was recovered exclusively in the cytosolic fraction (Figure $5 \mathrm{~A}$ ), the mitochondrial fraction appeared to be free of soluble fraction contaminants. As expected, the signal of ATPase occurred predominantly in the MF (Figure 5A).

In untreated cells, rpL3 was significantly more abundant in the CF but it was also detected in the MF. Specifically, the quantitative analysis revealed that about $75 \%$ of $\mathrm{rpL} 3$ was associated with the CF fraction and $25 \%$ in MF (Figure 5A). Of note, in 5-FU treated cells, the association of $\mathrm{rpL} 3$ to the mitochondria was more pronounced compared to that observed in untreated cells ( $40 \%$ vs $25 \%$ ). Analysis of subcellular distribution of rpL7a and S19, two arbitrary proteins of large and small subunit respectively, between $\mathrm{CF}$ and MF of 5-FU treated cells by western blotting shows that rpL7a and S19 are not present in the MF, indicating that the rpL3 localizes into the mithocondrion as form not associated to ribosome (Supplementary Figure S1).

The analysis of the distribution of CBS in the CF versus the MF revealed that in untreated cells, $\mathrm{CBS}$ was exclusively detected in the CF (Figure 5A). The induction of nucleolar stress mediated by the treatment of cells with 5-FU affected the distribution of CBS in the distinct pools. 


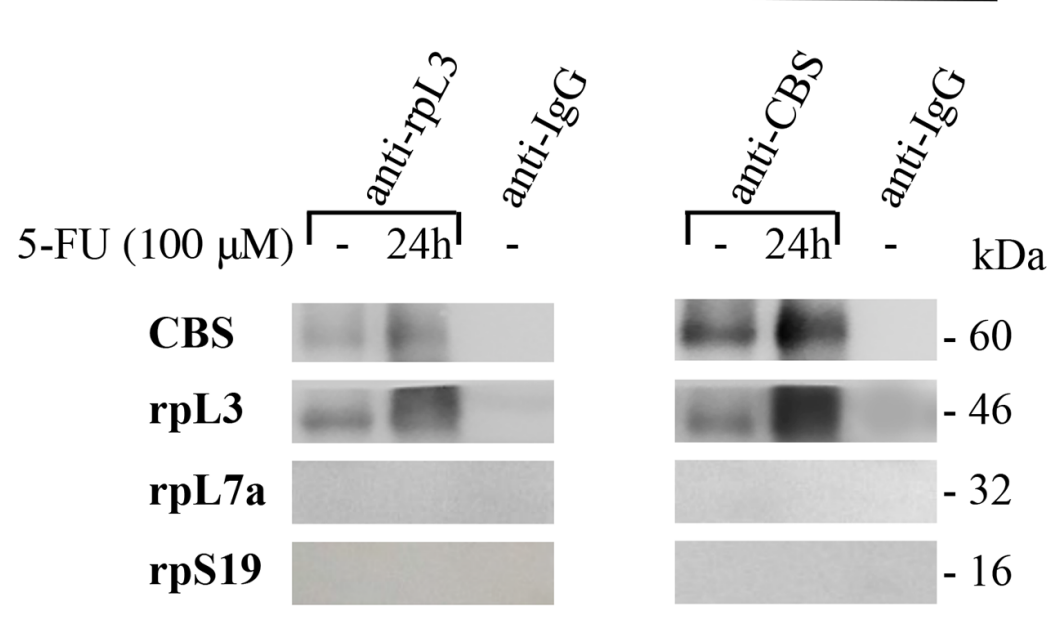

B
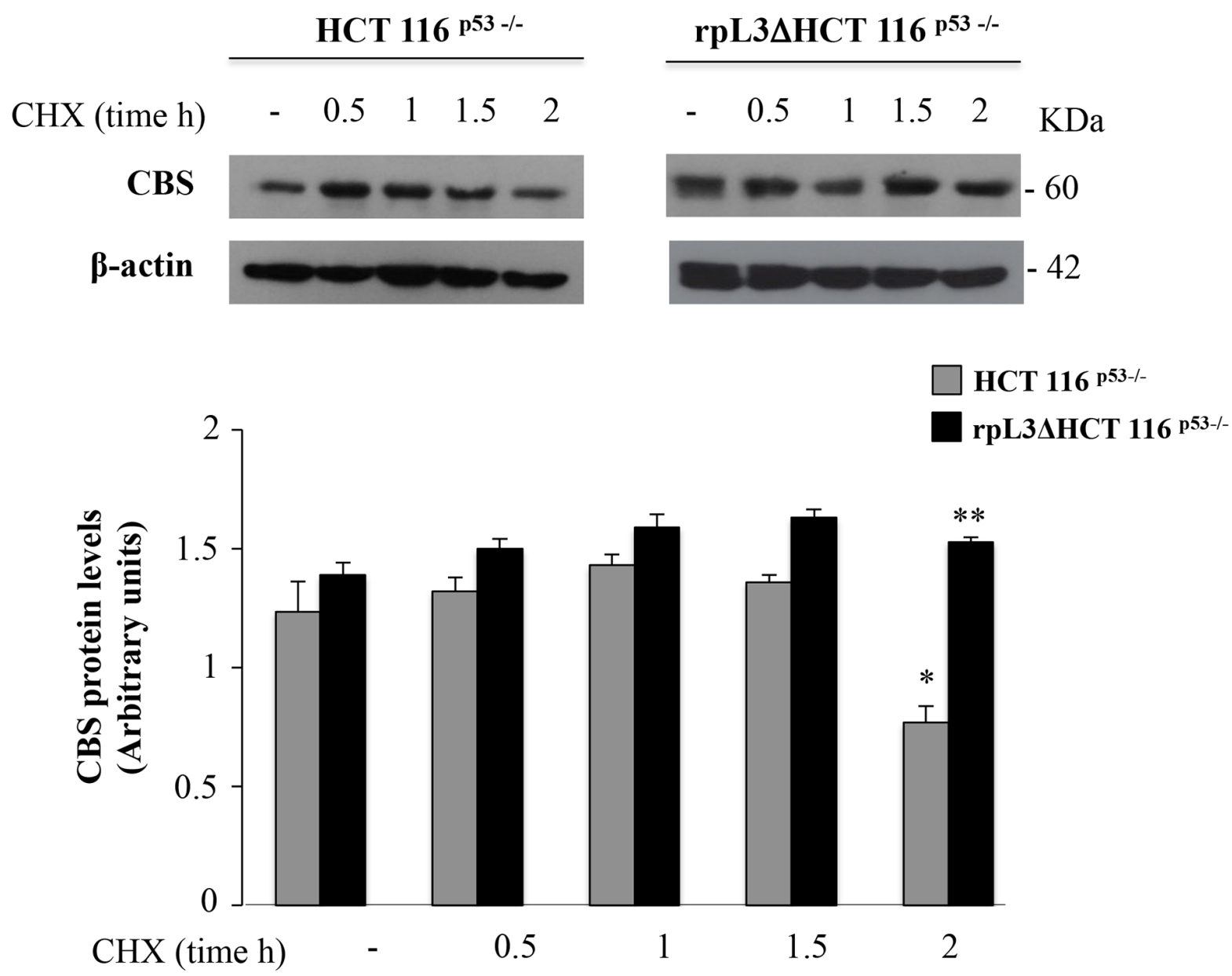

Figure 3: rpL3 interacts with CBS and negatively affects its half-life. A. In vivo binding of rpL3 and CBS. rpL3 or CBS were specifically immunoprecipitated from cell extracts with antibodies against the endogenous rpL3 and CBS. Immunoprecipitates were separated by SDS-PAGE and immunoblotted with antibodies versus the indicated proteins. Note the absence of signal in IgG immunocomplex. B. HCT $116^{\mathrm{p} 53-/-}$ and $\mathrm{rpL} 3 \Delta \mathrm{HCT} 116^{\mathrm{p} 53-/-}$ cells were treated with CHX for $0.5,1,1.5$ and $2 \mathrm{~h}$. After the treatment, cell lysates were prepared and immunoblotted with anti-CBS. $\beta$-actin was used as control. Quantification of the signals is shown. ${ }^{*} \mathrm{P}<0.05$ vs. untreated HCT $116^{\mathrm{p53--}-\mathrm{cells} ;}{ }^{\#} \mathrm{P}<0.01$ vs. HCT $116^{\mathrm{p53-/}}$ cells treated with CHX for $2 \mathrm{~h}$. 
Quantification of the signal for CBS showed that, after 5 -FU treatment, about $16 \%$ of the signal occurred in the MF (Figure 5A). These findings clearly indicate a specific association of rpL3 and CBS with the mitochondria during drug-induced nucleolar stress.
Next, in order to verify whether the shift of CBS from the $\mathrm{CF}$ to the MF was mediated by rpL3, the CBS mitochondrial content was evaluated also in rpL3 $\Delta \mathrm{HCT}$ $116^{\mathrm{p} 53-1-}$ cells. Western blotting analysis of biochemical fractions from these cells after 5-FU treatment showed
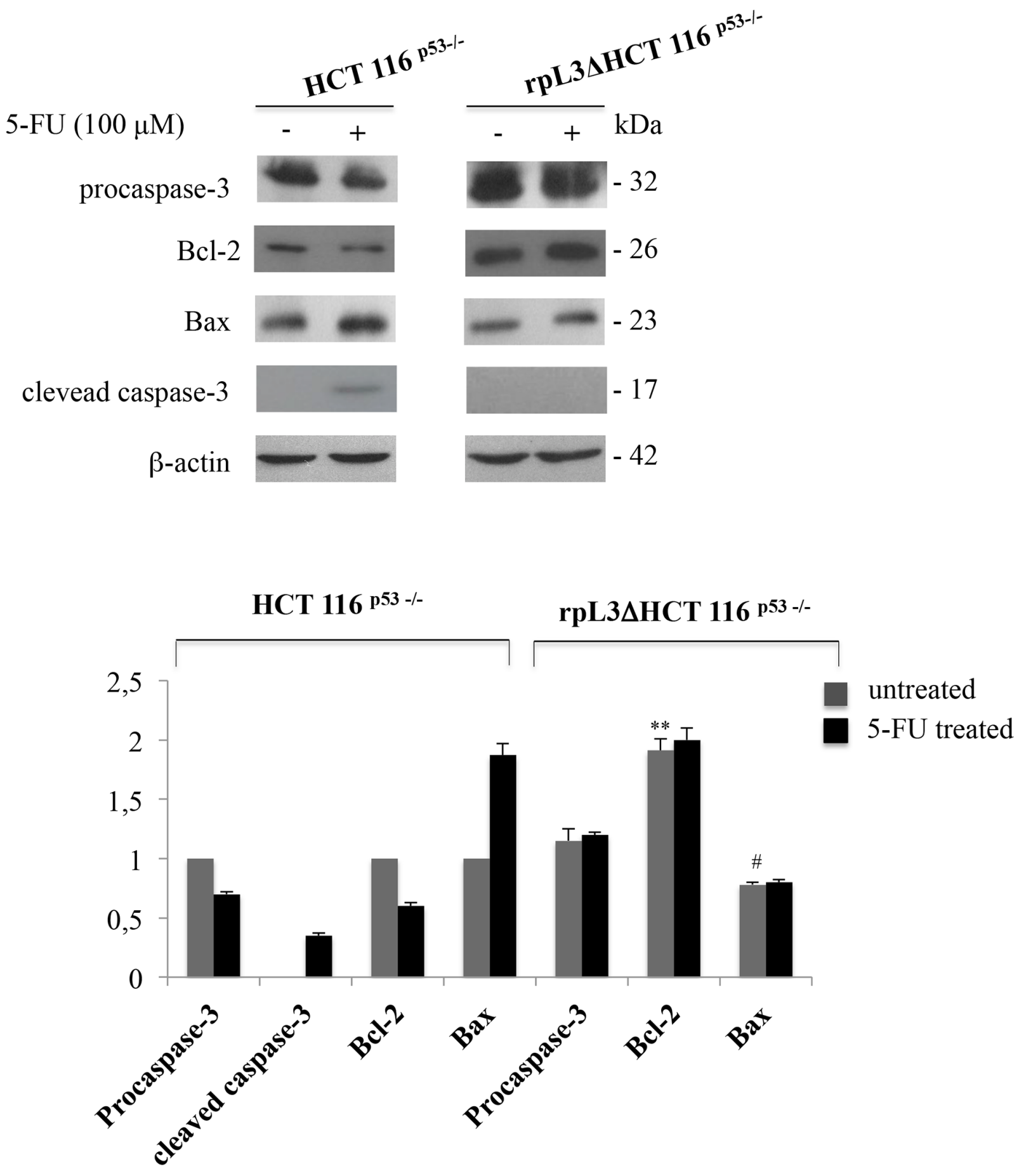

Figure 4: rpL3 activates mitochondrial apoptosis upon 5-FU treatment. Representative western blotting of procaspase-3, Bcl-2, Bax and active clevead caspase-3 protein expression. HCT $116^{\text {p53-- }}$ and rpL3 $\Delta$ HCT $116^{\text {p53-- }}$ cells were treated or not with $100 \mu \mathrm{M} 5$-FU for $24 \mathrm{~h}$. After the treatment, protein extracts from the samples were analyzed by western blotting with the indicated antibodies. $\beta$-actin was used as control. Quantification of the signals is shown. ${ }^{* *} \mathrm{P}<0.01 \mathrm{vs}$. Bcl-2 in untreated HCT $116^{\mathrm{p} 53-/ /}$ cells; ${ }^{\#} \mathrm{P}<0.05$ vs. Bax in untreated HCT $116^{\mathrm{p} 53-/-}$ cells. 
A
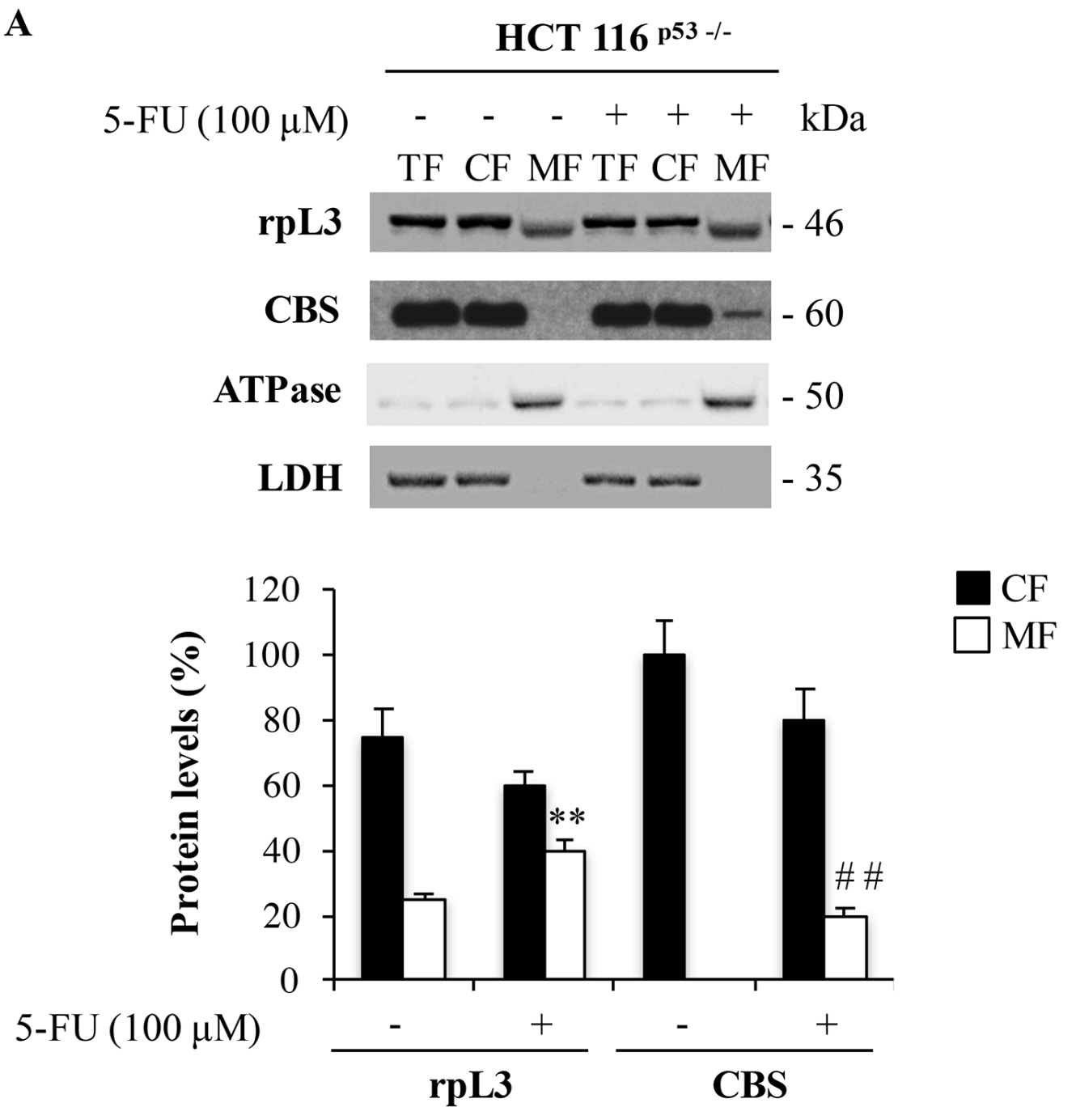

B

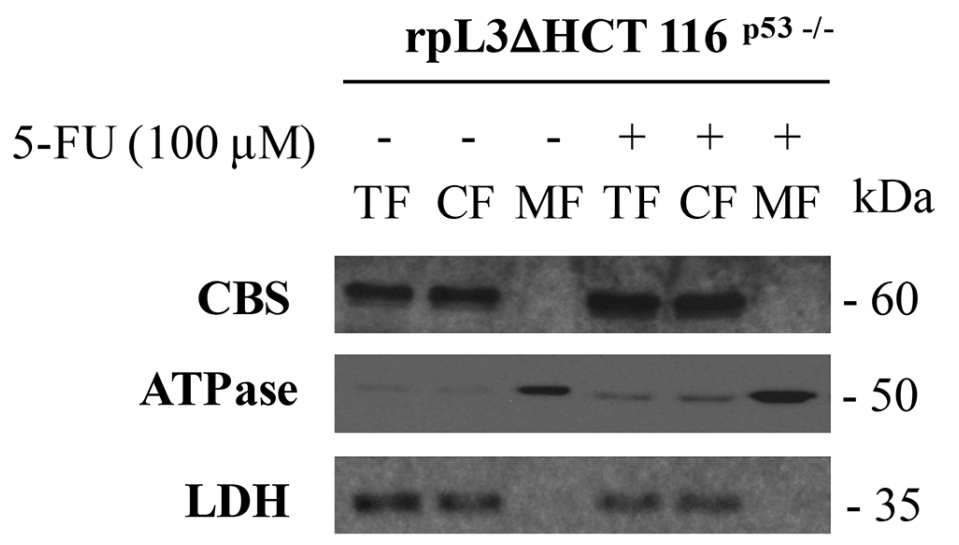

Figure 5: 5-FU induced rpL3 triggers CBS mitochondrial translocation. A. HCT $116^{\mathrm{p} 53-/-}$ and $\mathbf{B}$. rpL3 $3 \Delta \mathrm{HCT}^{116^{\mathrm{p} 53-/-}}$ cells were treated or not with $100 \mu \mathrm{M}$ 5-FU for $24 \mathrm{~h}$. After the treatment, cells were subjected to fractionation to obtain the cytosolic fraction (CF) and the mitochondrial fraction (MF). Protein extracts from the samples were analyzed by western blotting with antibodies against rpL3 and CBS. LDH and ATPase were used as controls for CF and MF, respectively. Quantification of the signals is shown. ${ }^{*} \mathrm{P}<0.01 \mathrm{vs}$. rpL3 in untreated MF; \#\#P<0.01 vs. CBS in untreated MF. 
the absence of the signal for CBS in MF fraction (Figure $5 B)$. These data strongly indicate that rpL3 was essential in mediating the association of CBS to mitochondria in condition of nucleolar stress.

\section{rpL3 mediates cytochrome c release after 5-FU treatment}

Release of cytochrome $\mathrm{c}$ from the mitochondria to the cytosol is a critical step in apoptotic cell death [23], thus we became interested to examine cytochrome c release to the cytosol in HCT $116^{\text {p53-/ }}$ and $\mathrm{rpL} 3 \Delta \mathrm{HCT}$ $116^{\text {p53-/ }}$ cells upon 5-FU treatment. To this aim, HCT $116^{\mathrm{p} 53-/-}$ and $\mathrm{rpL} 3 \Delta \mathrm{HCT} 116^{\mathrm{p} 53-/-}$ cells were subjected to biochemical fractionation to isolate the $\mathrm{CF}$ and $\mathrm{MF}$. Fractionation efficiency was evaluated by using LDH and ATPase as control of the $\mathrm{CF}$ and MF, respectively. Figure $6 \mathrm{~A}$ shows that in untreated HCT $116^{\mathrm{p} 53-/-}$ cells, a significant amount of cytochrome c was detected in the MF. $24 \mathrm{~h}$ after 5-FU treatment, a redistribution of cytochrome c between the subcellular compartments was observed. In fact, in this condition the decrease of cytochrome $\mathrm{c}$ in MF was associated to an increase of it in CF. Of interest, in rpL3 $\triangle$ HCT $116^{\text {p53-/ }}$ cells the treatment with 5-FU was not associated to cytochrome $\mathrm{c}$ redistribution betwen $\mathrm{CF}$ and MF (Figure 6B).

\section{CBS regulates migration and invasion of colon cancer cells upon 5-FU treatment}

In order to confirm the relevance of CBS in the cell response to 5-FU, we decided to perform gene silencing experiments. To this end, we generated a cell line stably silenced for CBS derived from HCT $116^{\mathrm{p} 53-/-}$ cells namely CBS $\triangle$ HCT $116^{\text {p53-/ }}$, in which CBS protein expression was abrogated using shRNA technology.

Supplementary Figure S2 shows the decrease of CBS levels in different clones. We chosed the cell clone expressing the lowest level of CBS for further experiments. We examined the effect of CBS silencing in the cell response to 5 -FU by a clonogenic assay. To this aim, HCT $116^{\mathrm{p} 53-/-}$ and CBS $\Delta$ HCT $116^{\mathrm{p} 53-/-}$ cells were treated with 5 -FU for $24 \mathrm{~h}$. Figure $7 \mathrm{~A}$ shows that in HCT $116^{\mathrm{p} 53-/-}$ cells, the colony number was reduced upon exposure to 5-FU thus confirming the ability of the drug to inhibit clonogenicity. It is noteworthy that in CBS $\triangle$ HCT $116^{\text {p53-/ }}$ cells the colony-forming activity upon 5-FU treatment was significantly reduced compared to the colony-forming activity of untreated cells (Figure 7A). These results suggest that the loss of CBS plays a critical role in cell response to 5-FU.

Moreover, we investigated the effect of CBS silencing on cell motility in HCT $116^{\text {p53-/- }}$ cells upon 5-FU exposure. Cell migration was determined using wound healing assay and quantitatively evaluated in terms of occupation rate of open wound (see Materials and
Methods). As indicated in Figure 7B, the wound healing ability of 5-FU treated HCT $116^{\mathrm{p} 53-/-}$ cells was reduced in time dependent manner compared to that observed in untreated cells. Likewise, the quantitative analysis showed that the open wound of 5-FU treated HCT $116^{\mathrm{p} 53-}$ ${ }^{-}$cells was decreased of about $10 \%$ and $50 \%$ compared to untreated cells after 8 and 24 h respectively. When CBS was depleted, the wound healing ability of 5-FU treated HCT $116^{\mathrm{p} 53-/}$ cells was markdely reduced, demonstrating that CBS depletion was able to furher decrease 5-FUreduced cell motility. In particular, the quantification indicated that the open wound of 5-FU treated CBS $\triangle \mathrm{HCT}$ $116^{\mathrm{p} 53-/-}$ cells was decreased of about $10 \%$ and $20 \%$ after 8 and $24 \mathrm{~h}$, respectively (Figure 7B).

All together these findings indicate that CBS inhibition promoted chemosensitization, decreased colony-forming potential in clonogenic assays and cell migration.

\section{DISCUSSION}

It is known that more than $50 \%$ of human cancers lack functional p53 [24]. Consequently, drugs triggering cell death in p53-null cells may have great potential in the treatment of many cancers. 5-FU is a drug able to induce nucleolar stress [4]. Recently, we have demonstrated that after nucleolar stress induced by 5-FU treatment in colon cancer cells lacking active p53, rpL3 is up-regulated and accumulated as ribosome free form needed to mediate 5-FU apoptotic cell response. In fact the loss of $\mathrm{rpL} 3$ makes chemotherapeutic drug ineffective [9]. Moreover, we have demonstrated that overexpression of $\mathrm{rpL} 3$ in cancer cells laking p53 induces cell cycle arrest or apoptosis by positively modulating the activity of p21 [8].

These finding strongly suggest that the knowledge of rpL3 status in relation to p53 status in colon cancers may have a significant value in terms of the efficacy of chemotherapy. The focus of the current study was to increase the knowledge on the relationship between alteration on rpL3 levels induced by nucleolar stress and activity of 5-FU for the treatment of the colon cancers laking p53; the full understanding of p53-independent pathways implicated in colon cancer molecular biology may provide new targets for cancer therapy.

The colon is known to synthesize and metabolize $\mathrm{H}_{2} \mathrm{~S}$ and to be exposed to exogenous $\mathrm{H}_{2} \mathrm{~S}$ as consequence of metabolic activity of luminal microbiota [25]. There are evidences supporting both the cytoprotective and cytotoxic effects of $\mathrm{H}_{2} \mathrm{~S}$ [26]. Recent data demonstrate that $\mathrm{H}_{2} \mathrm{~S}$ is implicated in human colorectal cancer development [27]. In addition, it has been recently reported a functional relation between $\mathrm{H}_{2} \mathrm{~S}$ production and $\mathrm{p} 21$ expression in colon cancer. In particular, an exogenously administered $\mathrm{H}_{2} \mathrm{~S}$ donor, NaHS, inhibited significantly p21 expression leading to colon cancer cell proliferation [28]. All these findings prompted us to explore the hypothesis of a new 
rpL3 dependent stress response pathway involving CBS. Specifically, we wondered whether CBS was involved in rpL3-mediated stress pathway upon 5-FU treatment in p53 null colon cancer HCT $116^{\mathrm{p} 53-/-}$ cells. 5-FU treatment of HCT $116^{\mathrm{p} 53-/-}$ cells caused a reduction in CBS expression levels and $\mathrm{H}_{2} \mathrm{~S}$ production. Conversely, a marked increase of CBS expression and $\mathrm{H}_{2} \mathrm{~S}$ biosynthesis was observed upon rpL3 silencing and 5-FU treatment indicating that the alteration in $\mathrm{CBS}$ and $\mathrm{H}_{2} \mathrm{~S}$ levels after drug treatment is rpL3-dependent (Figure 1). According to this, the analysis of cell cycle distribution of HCT $116^{\mathrm{p} 53-/-}$ cells stably depleted of rpL3 led us to exclude that observed effects are consequence of cell cycle alterations (Supplementary
Figure S3). In addition, unchanged expression levels of other ribosomal proteins in this cell line indicate that the obtained results are not due to ribosome deficiency (Supplementary Figure S4).

Analysis of CBS mRNA levels and ChIP experiments in HCT $116^{\mathrm{p} 53-/-}$ cells and $\mathrm{rpL} 3 \Delta \mathrm{HCT} 116^{\mathrm{p} 53-}$ /- cells, untreated or treated with 5-FU, imply a negative role of rpL3 in CBS gene transcription (Figure 2). It is well-known that CBS promoter contains Sp1 binding sites and that $\mathrm{Sp} 1$ is essential for its transactivation [16]. Interestingly, rpL3 associates with Sp1 and this association is necessary for rpL3-mediated p21 promoter transactivation [8]. Here, we demonstrate that $\mathrm{rpL} 3$
A

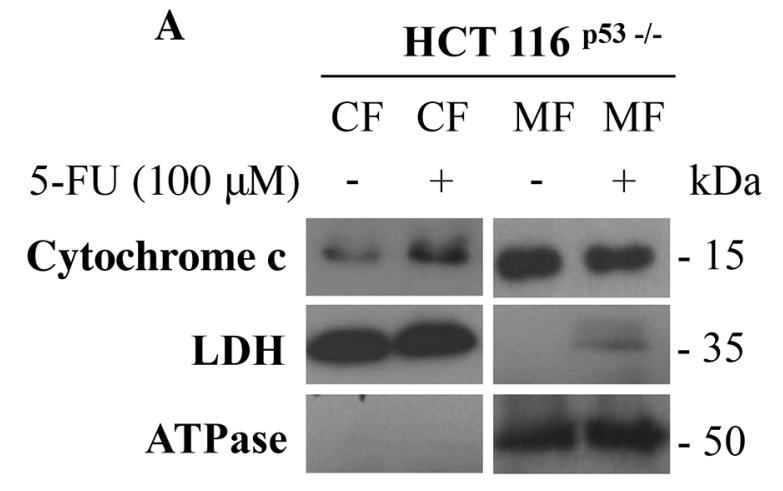

B

$$
\frac{\text { rpL3 } \mathbf{H C T} \mathbf{1 1 6}^{\mathbf{p 5 3 - / -}}}{\text { CF } \mathrm{CF} \text { MF MF }}
$$

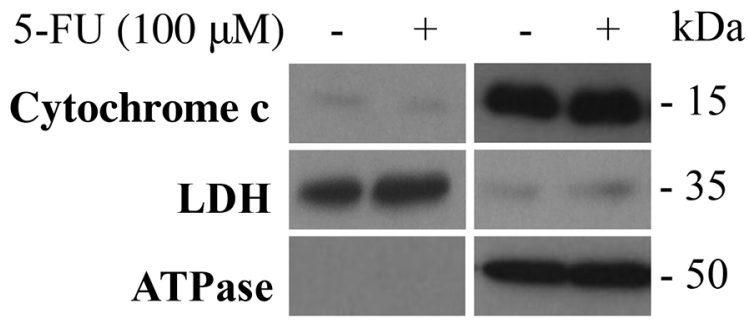

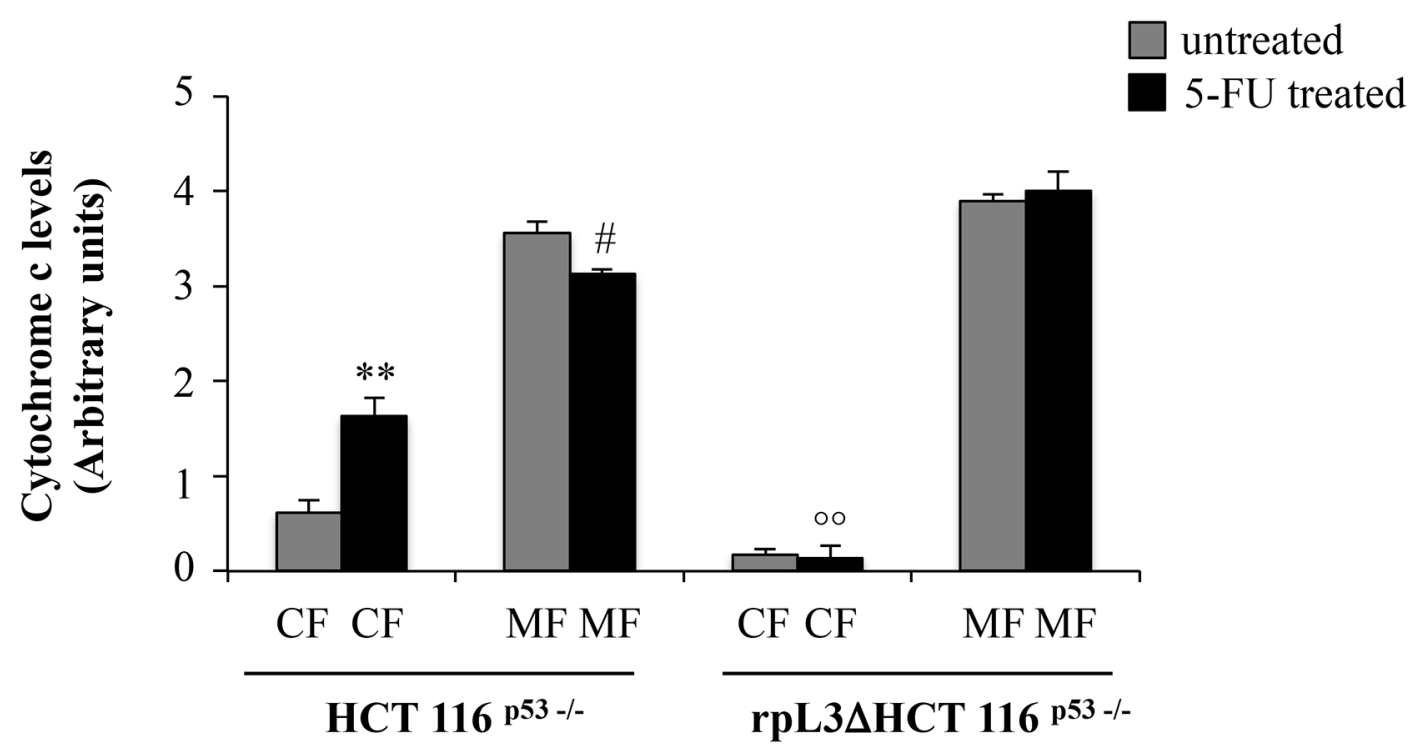

Figure 6: rpL3 translocation upon 5-FU treatment mediates the release of cytochrome c from mitochondria. Representative western blotting of cytochrome c protein expression. A. HCT $116^{\text {p53-/ }}$ and B. rpL3 $\Delta$ HCT $116^{\text {p53-/ }}$ cells were treated or not with $100 \mu \mathrm{M} \mathrm{5-FU}$ for $24 \mathrm{~h}$. After the treatment, cells were subjected to fractionation to obtain the cytosolic fraction (CF) and the mitochondrial fraction (MF). Protein extracts from the samples were analyzed by western blotting with antibodies against cytochrome c. LDH and ATPase were used as controls for CF and MF, respectively. Quantification of the signals is shown. $* * \mathrm{P}<0.01$ vs. cytochrome $\mathrm{C}$ in CF from untreated HCT $116^{\mathrm{p} 53-/-}$ cells; \#P $<0.05$ vs. cytochrome C in MF from untreated HCT $116^{\mathrm{p} 53-/-}$ cells; ${ }^{\circ} \mathrm{P}<0.01 \mathrm{vs}$. cytochrome $\mathrm{C}$ in MF from 5-FU treated HCT $116^{\mathrm{p} 53-/-}$ cells. 
A
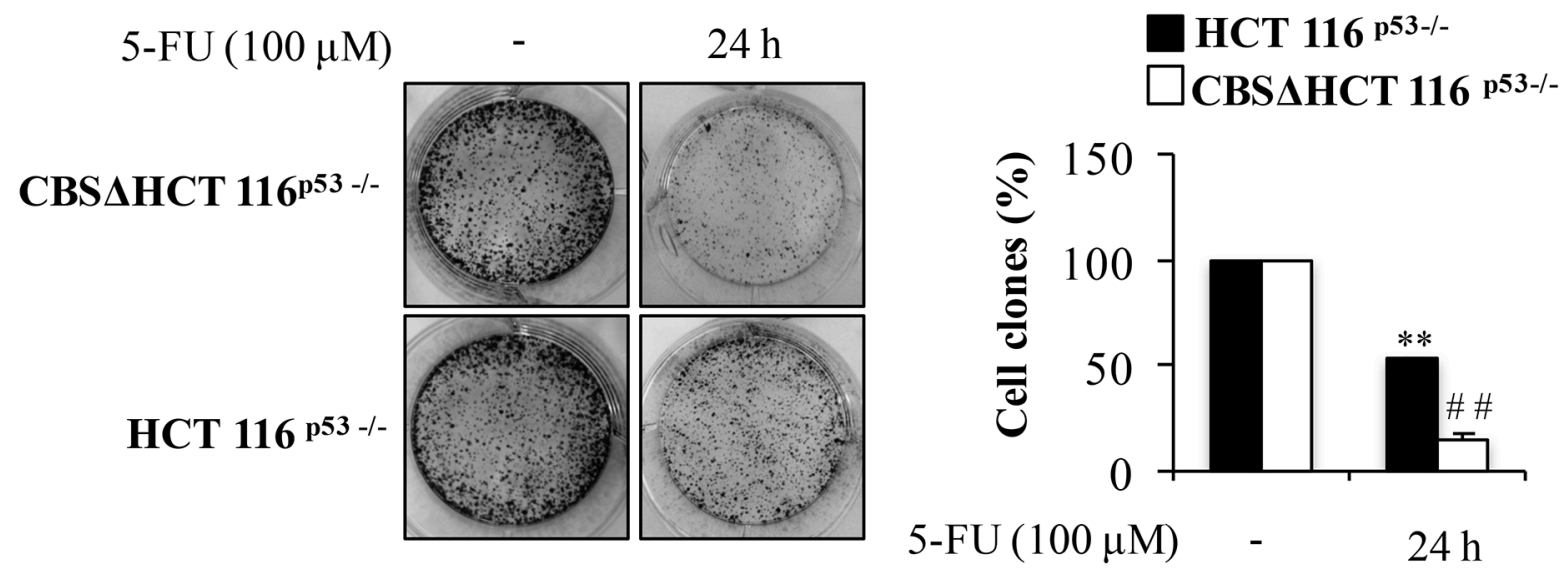

B
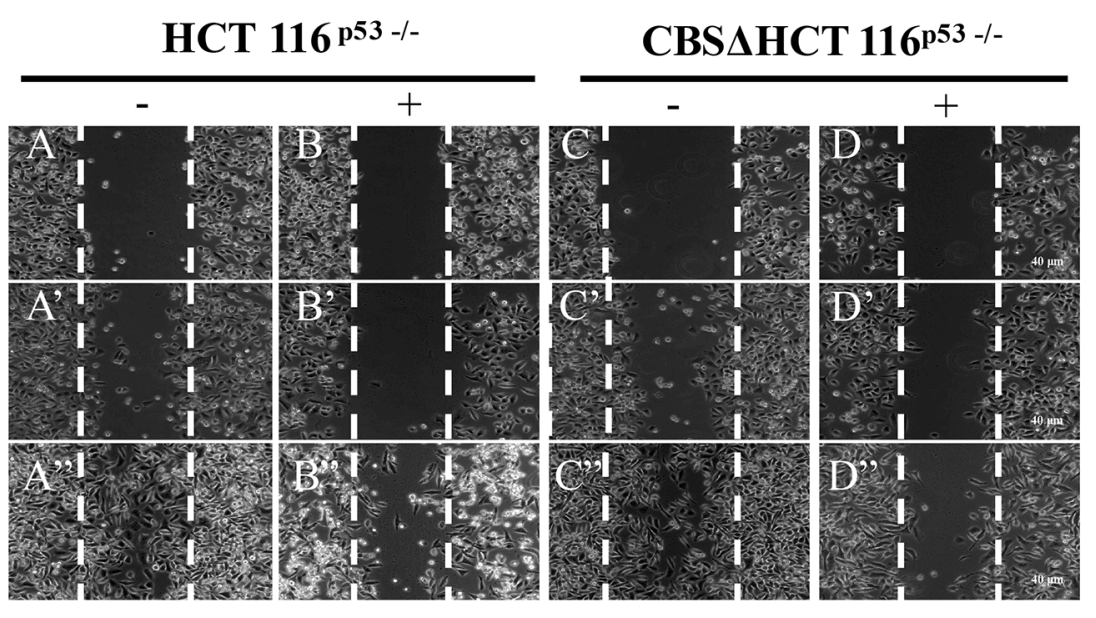

time
$0 \mathrm{~h}$
$8 \mathrm{~h}$
$24 \mathrm{~h}$

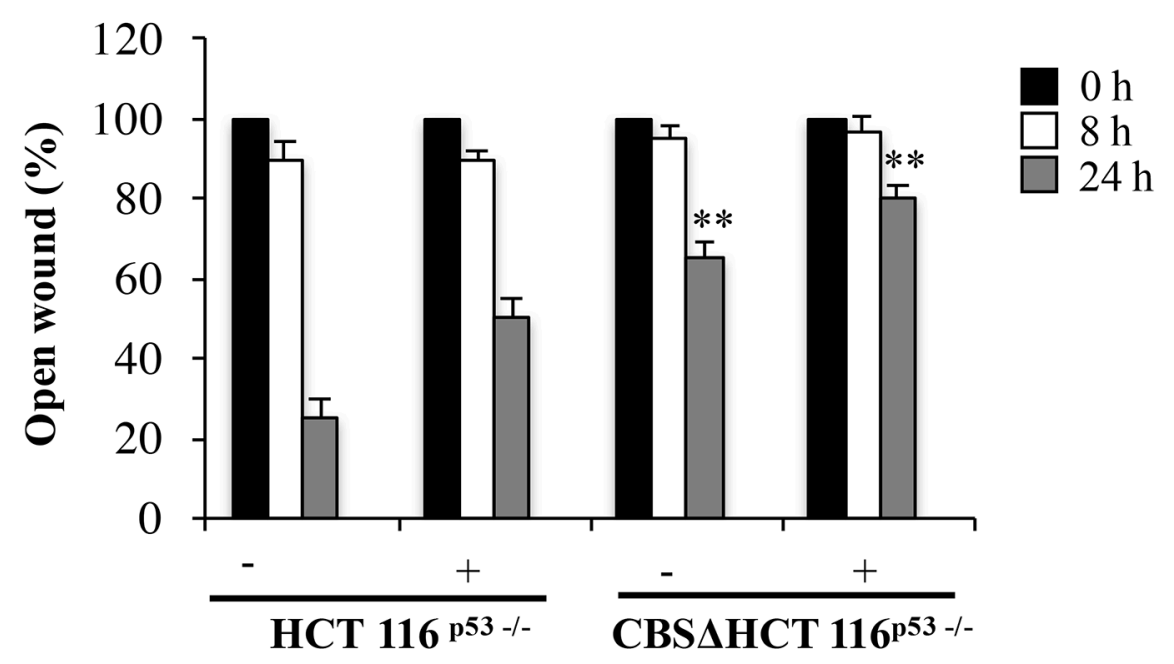

Figure 7: Depletion of CBS decreases cell proliferation and migration. A. Representative images of clonogenic analysis for cell proliferation in HCT $116^{\text {p33-/ }}$ and CBS $\triangle$ HCT $116^{\text {p53-/ }}$ cells after 5-FU treatment. ${ }^{* *} \mathrm{P}<0.01$ vs. untreated HCT $116^{\text {p53-/ }}$ cells; \#\#P $<0.01$ vs. untreated $\mathrm{rpL} 3 \Delta \mathrm{HCT} 116^{\mathrm{p53}-/}$ cells. B. Representative images of wound healing assay for cell proliferation in HCT $116^{\mathrm{p} 53-/}$ and CBS $\Delta \mathrm{HCT}$ $116^{\text {p53-l- }}$ cells after 5 -FU treatment. Wound widths were measured at 0,8 and $24 \mathrm{~h}$ on 3 fields per well and averaged. Data is expressed as the fold-decrease of area respect to controls (A, B, C, D) set as $100 \%$. ** $\mathrm{P}<0.01$ vs untreated HCT $116^{\mathrm{p} 33-/ /}$ cells. 
associates in vivo with $\mathrm{Sp} 1$ in condition of 5-FU treatment (Figure 2B). These findings led us to hypothesize that the binding of Sp1 to CBS promoter could be influenced by rpL3 levels; specifically we propose that rpL3 behaves as a negative regulatory factor of CBS transcription through its binding to Sp1. The formation of the complex rpL3-Sp1 could induce conformational changes in Sp1 promoting its release from the CBS promoter. Analysis of immunoprecipitate of rpL3 and CBS in HCT $116^{\mathrm{p} 53-/-}$ cell extracts treated or not with 5-FU showed that rpL3 and CBS coimmunoprecipitate together indicating that these proteins associate in vivo (Figure 3A). The stability of an enzyme might play an important role in the regulation of its activity. Here we demonstrated that $\mathrm{rpL} 3$ is able to reduce CBS protein stability (Figure 3B). All together these results demonstrate that ribosome free rpL3 reduces CBS protein levels after 5-FU treatment in colon cancer cells devoid of p53 by acting at both transcriptional and post-translational levels.

CBS protein does not contain a $\mathrm{NH}_{2}$ terminal signal to direct it to the mitochondria [29]. However, in the present study we show a 5-FU induced mitochondrial CBS traslocation in HCT $116^{\text {p53-/- }}$ cells (Figure 5A). In this process rpL3 plays a crucial role as in rpL3 $3 \mathrm{HCT}$ $116^{\mathrm{p} 53-/-}$ cells 5 -FU treatment failed to direct CBS into the mitochondria (Figure 5B). Previous studies have shown that Lon protease, a major degradation enzyme in mithocondria recognizes and degrades CBS enzyme [29]. Starting from these findings we hypothesize that $\mathrm{rpL} 3$ mediated translocation of CBS into the mitochondrion is associated to its degradation via Lon protease.

Cytochrome $\mathrm{c}$ is normally located in the intermembrane space of the mitochondrion, loosely bound to the inner membrane [30]. Although apoptosis can occur via cytochrome c-independent mechanisms, it is well established that release of cytochrome $\mathrm{c}$ into the cytosol results in caspase- 3 mediated activation of apoptosis [31]. Here we show a significant release of cytochrome $\mathrm{c}$ in the cytosol of 5-FU treated HCT $116^{\mathrm{p} 53-/-}$ cells (Figure 6) coupled to a significant increase in active cleaved caspase- 3 and a decrease in the Bcl-2/ Bax ratio (Figure 4). All these data are consistent with an increase of apoptosis induced upon 5-FU treatment. Most notably, silencing of rpL3 in HCT $116^{\mathrm{p} 53-/-}$ cells completely abolished these effects. Indeed, in these cells we observed a significant increase in Bcl-2 levels, and 5-FU treatment did not modify mitochondrial Bax levels. This resulted in an increase in the $\mathrm{Bcl}-2 / \mathrm{Bax}$ ratio, a response that would be protective against apoptosis. Consistent with this, in the cytosol of 5-FU treated rpL3 3 HCT $116^{\text {p53-/ }}$ cells there was lack of release of citochrome c. All togheter these results indicate that rpL3 is a major player in the apoptotic activity of 5-FU.

In order to further characterize the role of CBS in rpL3-mediated cell response to 5-FU, we stably silenced CBS in HCT $116^{\mathrm{p} 53-/-}$ cells.
CBS inhibition did not cause alteration of cell cycle distribution (Supplementary Figure S3) but specifically promoted chemosensitization, in fact we observed a decreased colony-forming potential in clonogenic assays and inibition of cell migration (Figure 7).

On the basis of these results, we propose a working model in which following 5-FU treatment, ribosome free rpL3 controls CBS expression at both transcriptional and post-translational levels. In the nucleus, under 5-FU induced nucleolar stress, the ribosome free rpL3 is able to activate p21 promoter [9-10] and to inhibit CBS transcription. We have previously demonstrated that $\mathrm{Sp} 1$ is a key component of rpL3-mediated p21 transactivation. Therefore it is likely that rpL3 may bind and sequester Sp1 from CBS promoter with consequent downregulation of CBS expression. At the same time, rpL3 could recruit $\mathrm{Sp} 1$ on $\mathrm{p} 21$ promoter thereby activating $\mathrm{p} 21$ expression (Figure 8).

In the cytoplasm, ribosome free rpL3 associates with CBS to shuttle it into the mitochondria. We hypothesyze that rpL3-CBS interaction leads to destabilization of mitochondrial CBS and, in turn, to a reduction in $\mathrm{H}_{2} \mathrm{~S}$ biosynthesis. Several reports indicate an anti-apoptotic action of $\mathrm{H}_{2} \mathrm{~S}$ [32]. Along this line, the decrease in $\mathrm{H}_{2} \mathrm{~S}$ levels correlates with cytochrome c release from mitochondria, increased $\mathrm{Bax} / \mathrm{Bcl} 2$ ratio and caspase activation (Figure 8).

In summary, we identified free rpL3 as a key regulator of $\mathrm{CBS}$ expression acting at transcriptional and post-translational levels. Taking into account the important role of CBS-derived $\mathrm{H}_{2} \mathrm{~S}$ in tumor growth and proliferation it is evident that a fine regulation of CBS levels is required to prevent cancer as well as in response to chemotherapy. In the light of our findings, we suggest that the association of rpL3 mediated trascriptional and post-translational regulation of CBS levels might represent a way to finetune the amount of this protein to the appropriate levels. In other words, this fine regulation might provide a means with which to lower the threshold of CBS expression below what would otherwise be possible by modulating the transcription rate alone.

As a newly identified CBS repressor, rpL3 may be a potential cytotoxic agent against colon cancers lacking of $\mathrm{p} 53$. The relevance of these results suggests that therapeutic strategies aimed to upregulating rpL3 may be effective in the treatment of these tumors. Recently, we have developed novel polymeric nanoparticles based on a core of poly(lactic-co-glycolic) acid (PLGA) and a polymer shell of Hyaluronan (HA) and Polyethyleneimine (PEI) that represent a very promising system for the targeted delivery of drug combinations taking advantage of the shell and core properties [33]. At the present, the challenge is to use these nanoparticles as platform to deliver the conventional drug 5-FU and the proapoptotic protein $\mathrm{rpL} 3$ for the treatment of colon cancers lacking functional p53. 


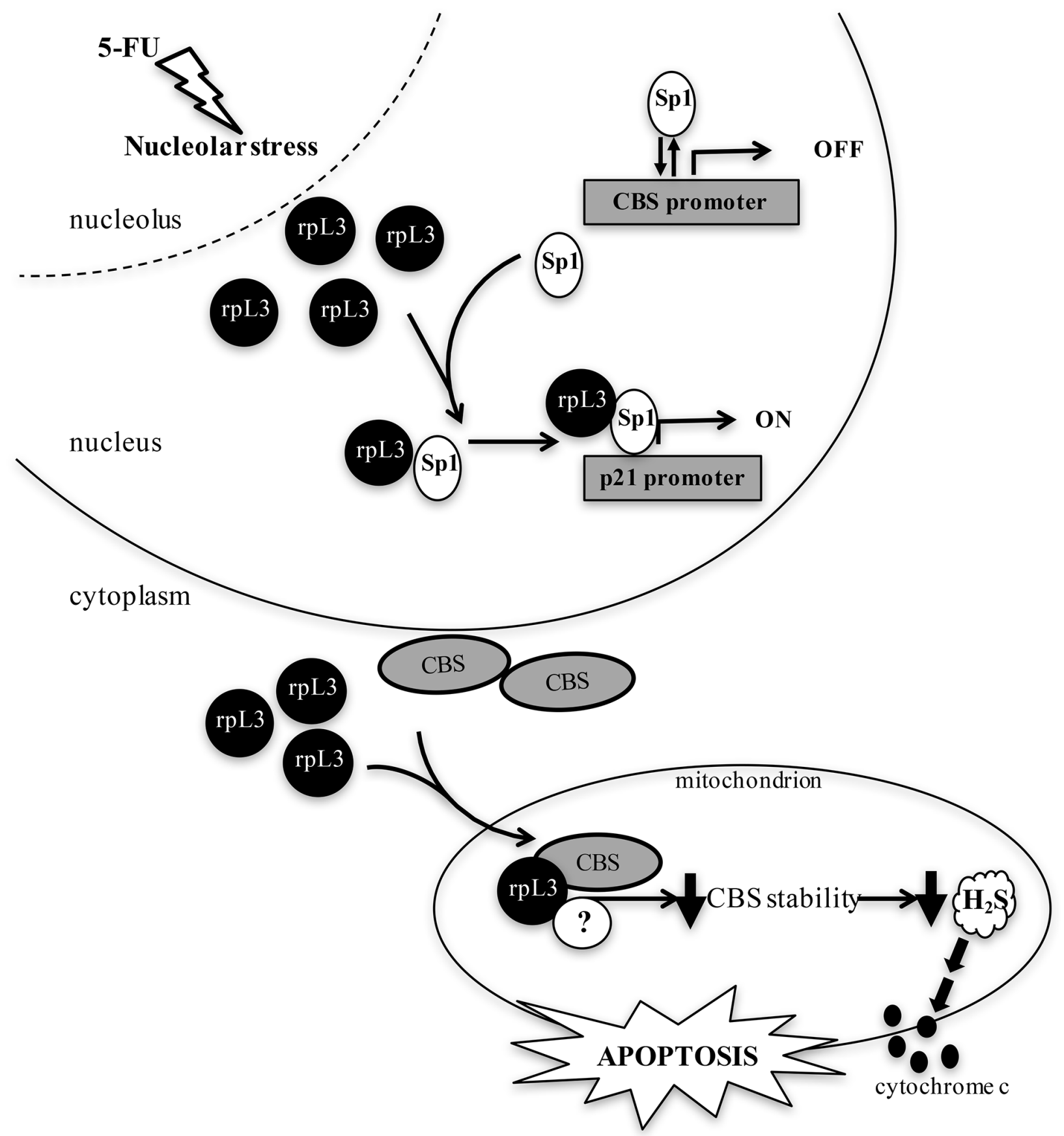

Figure 8: Schematic representation of proposed model. 5-FUinduced nucleolar stress caused an induction of rpL3 as ribosomefree form. In response to 5-FU, ribosome free rpL3 becomes a regulator of CBS expression. At transcriptional level, rpL3 binds Sp1 and causes its release from CBS promoter. At the same time, rpL3 could recruit Sp1 on p21 promoter to induce its trans-activation At posttranslational level, rpL3 binds CBS and trigger it into the mitochondria for degradation. rpL3 effects associate to cytochrome c release, increase of $\mathrm{Bax} / \mathrm{Bcl} 2$ ratio and caspase activation.

\section{MATERIALS AND METHODS}

\section{Cell cultures, transfections and drug treatments}

HCT $116^{\text {p53-/ }}$ cells and rpL3 $\Delta$ HCT $116^{\text {p33-/ }}$ cells, derived from HCT $116^{\mathrm{p} 53-/}$ cell line and stably silenced for rpL3, were cultured in Dulbecco's Modified Eagle's Medium (DMEM) with glutamax (Invitrogen, Carlsbad,
California) supplemented with $10 \%$ fetal bovine serum (FBS), 2 mM L-glutamine, penicillin-streptomycin $50 \mathrm{U} /$ $\mathrm{ml}$ and $0.5 \mu \mathrm{g} / \mathrm{ml}$ puromycin (Sigma-Aldrich).

CBS $\triangle \mathrm{HCT} 116^{\mathrm{p} 53-/}$ cell line was obtained from

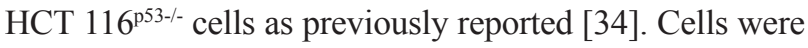
transfected with $2 \mu \mathrm{g}$ of different shRNA CBS plasmids (Sigma-Aldrich) by using Lipofectamin 2000 (Life Technologies) according to the manufacturer's instructions. 
Stable clones were selected in medium containing $1 \mathrm{mg} / \mathrm{ml}$ of Puromicin (Sigma-Aldrich) and assayed for the detection of CBS expression level by western blotting.

shRNA transfections were performed in cells as previously described [34].

Drug treatments were performed by adding to cells $100 \mu$ M 5-FU (Sigma-Aldrich, St. Louis, MO, USA), CHX

\section{Cell fractionation}

To analyze the subcellular distribution of rpL3 and CBS cells were separated into Cytosolic fraction (CF) and Mitochondrial fraction (MF) using a modified protocol [35]. Briefly, cells from three $100-\mathrm{mm}$ plate $(2 \times 107$ cells $)$ were washed with icecold PBS $1 \mathrm{X}$ and treated with 900 $\mu \mathrm{l}$ of ice cold isolation buffer ( $0,1 \mathrm{M}$ TRIS-MOPS, $0,1 \mathrm{M}$ EDTA-Tris, $1 \mathrm{M}$ sucrose). The cell suspension was placed in a glass potter, stroked 40 times and centrifuged at $600 \mathrm{xg}$ for $10 \mathrm{~min}$ at $4^{\circ} \mathrm{C}$. The supernatant obtained under these conditions was centrifuged at $7000 \mathrm{xg}$ for $10 \mathrm{~min}$ at $4^{\circ} \mathrm{C}$ and the recovered supernatant was referred to as the $\mathrm{CF}$. The pellet was resuspended in $200 \mu \mathrm{l}$ of ice-cold isolation buffer and then centrifuged at $7000 \mathrm{xg}$ at $4^{\circ} \mathrm{C}$ for $10 \mathrm{~min}$. The resulting pellet was resuspended in $50 \mu \mathrm{l}$ of ice-cold isolation buffer and referred to as the MF.

\section{Immunoprecipitation and western blotting}

Immunoprecipitation assay was performed as previously reported [36]. Briefly, $1 \mathrm{mg}$ of HCT $116^{\mathrm{p} 53-/ \mathrm{-}}$ whole cell lysate was incubated with $30 \mu \mathrm{l}$ of protein $\mathrm{A} / \mathrm{G}$ agarose beads coated with $5 \mu \mathrm{g}$ of anti-rpL3 (Primm, Milan, Italy) or anti-CBS (Santa Cruz Biotechnology) at $4{ }^{\circ} \mathrm{C}$ for $12 \mathrm{~h}$. The beads were washed and boiled in the SDS sample buffer. The eluted proteins were loaded on 12\% SDS-PAGE and detected by western blotting as previously reported [37, 38]. Aliquots of protein samples $(30 \mu \mathrm{g})$ were resolved by $12 \%$ SDS-gel electrophoresis and transferred into nitrocellulose filters. The membranes were blocked in PBS, $0.1 \%$ Triton (Santa Cruz). The proteins were visualized with enhanced chemiluminescence detection reagent according to the manufacturer's instructions (Pierce, Rockford, Illinois).

The membranes were challenged with anti-rpL3 and anti-rpL7a (Primm, Milan, Italy), anti-Sp1, anti-CBS, antiBcl-2, anti-Bax, anti-caspase 3 and anti- $\beta$-actin, anti-rpS19 (Santa Cruz Biotechnology). Proteins were visualized with enhanced chemiluminescence detection reagent according to the manufacturer's instructions (Pierce, Rockford, Illinois).

\section{Chromatin immunoprecipitation and Flow cytometry}

Chromatin immunoprecipitation asssay and Flow cytometry analysis were performed as previously reported [9].

\section{Clonogenic assay}

For clonogenic assay, cells $\left(4 \times 10^{3}\right.$ in 6-well multidishes) were plated in triplicate and treated with 5 -FU $(100 \mu \mathrm{M})$ for $24 \mathrm{~h}$ or not. After 10 days, colonies were stained with $1 \%$ methylene 490 blue in $50 \%$ ethanol as previously reported [10].

\section{Wound healing assay}

Cell motility was assessed using a wound healing assay. Cells $\left(1 \times 10^{6}\right.$ per well $)$ were treated with 5 -FU $(100 \mu \mathrm{M})$ for $24 \mathrm{~h}$ or not. The confluent monolayer cells were then carefully wounded using a sterilized pipette tip. Monolayer cells were photographed at 0,8 and $24 \mathrm{~h}$ with an objective 10X. Quantitative analysis of wound assay was performed by measuring the gap area. The gap area was defined by using ImageJ Software (National Institute of Health, USA). Data is expressed as the fold-decrease of area respect to controls set as $100 \%$. Bars represent the mean of triplicate experiments; error bars represent the standard deviation.

\section{Statistical analysis}

Error bars represent mean \pm SEM from $n=3$ biological replicates. Statistical comparisons were made by Student t-test and one-way ANOVA followed by Bonferroni's test for multiple comparisons. $\mathrm{P}<0.05$ was considered significant, $\mathrm{P}<0.001$ was considered highly significant.

\section{ACKNOWLEDGMENTS}

We thank Prof. G. Cirino for critical reading of the manuscript.

\section{CONFLICTS OF INTEREST}

The authors declare no conflict of interest.

\section{GRANT SUPPORT}

This work was supported by Ministero della Università e della Ricerca (MIUR) PRIN 2010 (4 AE23N_006) to GR, Italy

\section{REFERENCES}

1. Haggar FA, Boushey RP. Colorectal cancer epidemiology: incidence, mortality, survival, and risk factors. Clin Colon Rectal Surg. 2009; 22:191-7.

2. Longley DB, Latif T, Boyer J, Allen WL, Maxwell PJ, Johnston PG. The interaction of thymidylate synthase expression with $\mathrm{p} 53$-regulated signaling pathways in tumor cells. Semin Oncol. 2003; 30:3-9. 
3. Tanaka F, Fukuse T, Wada H, Fukushima M. The history, mechanism and clinical use of oral 5-fluorouracil derivate chemotherapeutic agents. Curr Pharm Biotechnol. 2000; 1:3727-34.

4. Sun XX, Dai MS, Lu H. 5-fluorouracil activation of p53 involves an MDM2-ribosomal protein interaction. J Biol. Chem. 2007; 26:2707-16.

5. Greenblatt MS, Bennett WP, Hollstein M, Harris CC. Mutations in the p53 tumor suppressor gene: clues to cancer etiology and molecular pathogenesis. Cancer Res. 1994; 54:4855-4878.

6. Muller PA, Vousden KH. Mutant p53 in cancer: new functions and therapeutic opportunities. Cancer Cell. 2014; 25:304-317.

7. Scartozzi M, Maccaroni E, Giampieri R, Pistelli M, Bittoni A, Del Prete M, Berardi R, Cascinu S. 5-Fluorouracil pharmacogenomics: still rocking after all these years? Pharmacogenomics. 2011; 12:251-265.

8. Russo A, Esposito D, Catillo M, Pietropaolo C, Crescenzi E, Russo G. Human rpL3 induces G(1)/S arrest or apoptosis by modulating p21 (waf1/cip1) levels in a p53-independent manner. Cell Cycle. 2013; 12:76-87.

9. Esposito D, Crescenzi E, Sagar V, Loreni F, Russo A, Russo G. Human rpL3 plays a crucial role in cell response to nucleolar stress induced by 5-FU and L-OHP. Oncotarget 2014; 5:11737-51. doi: 10.18632/oncotarget.2591.

10. Russo A, Pagliara V, Albano F, Esposito D, Sagar V, Loreni F, Irace C, Santamaria R, Russo G. Regulatory role of rpL3 in cell response to nucleolar stress induced by Act $\mathrm{D}$ in tumor cells lacking functional p53. Cell Cycle. 2016; 15:41-51.

11. Hellmich MR, Szabo C. Hydrogen Sulfide and Cancer. Handb Exp Pharmacol. 2015; 230:233-41.

12. Ostrakhovitch EA, Akakura S, Sanokawa-Akakura R, Goodwin S, Tabibzadeh S. Dedifferentiation of cancer cells following recovery from a potentially lethal damage is mediated by H2S-Nampt. Exp Cell Res. 2015; 330:135-50.

13. Zhao Y, Biggs TD, Xian M. Hydrogen sulfide (H2S) releasing agents: chemistry and biological applications. Chem Commun (Camb). 2014; 50:11788-805.

14. Szabo C, Coletta C, Chao C, Módis K, Szczesny B, Papapetropoulos A, Hellmich MR. Tumor-derived hydrogen sulfide, produced by cystathionine- $\beta$-synthase, stimulates bioenergetics, cell proliferation, and angiogenesis in colon cancer. PNAS. 2013; 12474-9.

15. Ge Y, Matherly LH, Taub JW. Transcriptional regulation of cell-specific expression of the human cystathionine betasynthase gene by differential binding of $\mathrm{Sp} 1 / \mathrm{Sp} 3$ to the $-1 \mathrm{~b}$ promoter. J Biol Chem. 2001; 276:43570-9.

16. Maclean KN, Kraus E, Kraus JP. The dominant role of Sp1 in regulating the cystathionine beta-synthase $-1 \mathrm{a}$ and $-1 \mathrm{~b}$ promoters facilitates potential tissue-specific regulation by Kruppel-like factors. J Biol Chem. 2004; 279:8558-66.
17. Bhattacharyya S1, Saha S, Giri K, Lanza IR, Nair KS, Jennings NB, Rodriguez-Aguayo C, Lopez-Berestein G, Basal E, Weaver AL, Visscher DW, Cliby W, Sood AK, Bhattacharya R, Mukherjee P. Cystathionine beta-synthase (CBS) contributes to advanced ovarian cancer progression and drug resistance. PLoS One. 2013; 8: e79167.

18. Russo A, Terrasi M, Agnese V, Santini D, Bazan V. Apoptosis: a relevant tool for anticancer therapy. Ann Oncol. 2006; 115-23.

19. Fan Y, Liu K, Wang Q, Ruan Y, Zhang Y, Ye W. Exendin-4 protects retinal cells from early diabetes in Goto-Kakizaki rats by increasing the $\mathrm{Bcl}-2 / \mathrm{Bax}$ and $\mathrm{Bcl}-\mathrm{xL} / \mathrm{Bax}$ ratios and reducing reactive gliosis. Mol Vis. 2014; 20:1557-68.

20. Susin SA, Lorenzo HK, Zamzami N, Marzo I, Snow BE, Brothers GM, Mangion J, Jacotot E, Costantini P, Loeffler M, Larochette N, Goodlett DR, Aebersold R, Siderovski DP, Penninger JM, Kroemer G. Molecular characterization of mitochondrial apoptosis-inducing factor. Nature. 1999; 397:441-6.

21. Hengartner MO. The biochemistry of apoptosis. Nature. 2000; 407:770-6.

22. Russo A, Cirulli C, Amoresano A, Pucci P, Pietropaolo C, Russo G. cis-acting sequences and trans-acting factors in the localization of mRNA for mitochondrial ribosomal proteins. Biochim Biophys Acta. 2008; 1779:820-9.

23. Babbitt SE, Sutherland MC, San Francisco B, Mendez DL, Kranz RG. Mitochondrial cytochrome c biogenesis: no longer an enigma. Trends Biochem Sci. 2015; 40:446-55.

24. Soussi T. The p53 tumor suppressor gene: from molecular biology to clinical investigation. Ann N Y Acad Sci. 2000; 910:121-37.

25. Flannigan KL, Agbor TA, Blackler RW, Kim JJ, Khan WI, Verdu EF, Ferraz JGP, Wallace JL. Impaired hydrogen sulphide synthesis and IL-10 signalling underlie hyperhomocysteinemia-associated exacerbation of colitis

26. Medani M, Collins D, Docherty NG, Baird AW, O'Connell PR, Winter DC. Emerging role of hydrogen sulfide in colonic physiology and pathophysiology. Inflamm Bowel Dis. 2011; 17:1620-5.

27. Szabo C. Gasotransmitters in cancer: from pathophysiology to experimental therapy. Nature Reviews Drug discovery. 2016; 15:185-203

28. Cai WJ, Wang MJ, Ju LH, Wang C, Zhu YC. Hydrogen sulfide induces human colon cancer cell proliferation: role of Akt, ERK and p21. Cell Biol Int. 2010; 34:565-72.

29. Teng H, Wu B, Zhao K, Yang G, Wu L, Wang R. Oxygensensitive mitochondrial accumulation of cystathionine $\beta$-synthase mediated by Lon protease. Proc Natl Acad Sci U S A. 2013; 110:12679-84.

30. Ott M, Robertson JD, Gogvadze V, Zhivotovsky B, Prrenius S. Cycromome c release from mitochondria proceeds by two-step process. PNAS. 2002; 99:1259-1263. 
31. Garrido C, Galluzzi L, Brunet M, Puig PE, Didelot C, Kroemer G. Mechanisms of cytochrome c release from mitochondria. Cell Death Differ. 2006; 13:1423-33.

32. Li-Fang $\mathrm{Hu}$, Ming Lu, Peter Tsun Hon Wong, and Jin-Song Bian. Hydrogen Sulfide: Neurophysiology and Neuropathology. Antioxidants \& Redox Signaling. 2011; 15: 405-419.

33. Maiolino S, Russo A, Pagliara V, Conte C, Ungaro F, Russo G, Quaglia F. Biodegradable nanoparticles sequentially decorated with Polyethyleneimine and Hyaluronan for the targeted delivery of docetaxel to airway cancer cells. J Nanobiotechnology. 2015; 13:29.

34. d'Emmanuele di Villa Bianca R, Mitidieri E, Esposito D, Donnarumma E, Russo A, Fusco F, Ianaro A, Mirone V, Cirino G, Russo G, Sorrentino R. Human Cystathionine$\beta$-Synthase Phosphorylation on Serine227 Modulates Hydrogen Sulfide Production in Human Urothelium. PLoS One. 2015; 10:e136859.
35. Frezza C, Cipolat S, Scorrano L. Organelle isolation: functional mitochondria from mouse liver, muscle and cultured fibroblasts. Nat Protoc 2007; 2:287-295.

36. Russo A, Catillo M, Esposito D, Briata P, Pietropaolo C, Russo G. Autoregulatory circuit of human rpL3 expression requires hnRNP H1, NPM and KHSRP. Nucleic Acids Res. 2011; 39:7576-7585.

37. Miniaci MC, Irace C, Capuozzo A, Piccolo M, Di Pascale A, Russo A, Lippiello P, Lepre F, Russo G, Santamaria R. Cysteine Prevents the Reduction in Keratin Synthesis Induced by Iron Deficiency in Human Keratinocytes. J Cell Biochem. 2016; 117:402-12.

38. De Filippis D, Russo A, De Stefano D, Cipriano M, Esposito D, Grassia G, Iuvone T. Palmitoylethanolamide inhibits rMCP-5 expression by regulating MITF activation in rat chronic granulomatous inflammation. Eur J Pharmacol. 2014; 725:64-69. 